\title{
AFR \\ 70,1 \\ Assessing the potential value for an automated dairy cattle body condition scoring system through stochastic simulation
}

\author{
J.M. Bewley, M.D. Boehlje, A.W. Gray, H. Hogeveen, S.J. Kenyon, \\ S.D. Eicher, and M.M. Schutz \\ (Information about the authors can be found at the end of the paper)
}

\begin{abstract}
Purpose - The purpose of this paper is to develop a dynamic, stochastic, mechanistic simulation model of a dairy business to evaluate the cost and benefit streams coinciding with technology investments. The model was constructed to embody the biological and economical complexities of a dairy farm system within a partial budgeting framework. A primary objective was to establish a flexible, user-friendly, farm-specific, decision-making tool for dairy producers or their advisers and technology manufacturers.

Design/methodology/approach - The basic deterministic model was created in Microsoft Excel (Microsoft, Seattle, Washington). The @ Risk add-in (Palisade Corporation, Ithaca, New York) for Excel was employed to account for the stochastic nature of key variables within a Monte Carlo simulation. Net present value was the primary metric used to assess the economic profitability of investments. The model was composed of a series of modules, which synergistically provide the necessary inputs for profitability analysis. Estimates of biological relationships within the model were obtained from the literature in an attempt to represent an average or typical US dairy. Technology benefits were appraised from the resulting impact on disease incidence, disease impact, and reproductive performance. In this paper, the model structure and methodology were described in detail.

Findings - Examples of the utility of examining the influence of stochastic input and output prices on the costs of culling, days open, and disease were examined. Each of these parameters was highly sensitive to stochastic prices and deterministic inputs.
\end{abstract}

Originality/value - Decision support tools, such as this one, that are designed to investigate dairy business decisions may benefit dairy producers.

Keywords Investment appraisal, Net present value, Agriculture, Stochastic processes, Modelling

Paper type Research paper

\section{Introduction}

While dairy farmers are encouraged to make capital investments in labor saving technologies, the true economic benefits coupled with sequential and inter-related uncertainties make such investment decisions difficult. As an illustration of this type of decision, the list of precision dairy farming (PDF) technologies used for animal status monitoring and management continues to grow. Because of rapid development of new

Agricultural Finance Review Vol. 70 No. 1, 2010

pp. $126-150$

Emerald Group Publishing Limited 0002-1466

DOI $10.1108 / 00021461011042675$
The authors would like to express their gratitude to the following individuals for their assistance through discussions on methodology for specific parts of this model: Huybert Groenendaal, Nicolas Friggens, Paivi Rajala-Schultz, Patrick French, Gregg Hadley, and Robert Boyce. Furthermore, this work would not have been possible without the generous assistance provided by the experts who took the time to complete the expert opinion survey.

No copyright is associated with this paper because of the author's employment by the United States Federal Government at the time the paper was written. 
technologies and supporting applications, PDF technologies are becoming more feasible. For example, systems to monitor body condition score (BCS) are being developed, yet the economic implications of investment in this technology are not yet understood. Uncertainty is inherent in the decision to invest in an automated BCS system with regard to market conditions, technology performance, and the impact of the technology on dairy cow production and health.

Automated body condition scoring has been discussed extensively and extraction of BCS from digital images is feasible, though no commercial system is currently available (Coffey et al., 2003a; Bewley et al., 2008). Because changes in body fat (energy reserves) have considerable influence on dairy cow productivity, health, and reproduction, there is an unmistakable need for a monitoring system to facilitate the optimal management of these reserves in dairy cows. Historically, this technique, termed body condition scoring has been accomplished by visual or tactile observation of a cow by a trained professional. The usefulness and relative precision of BCS is welldocumented (Ferguson et al., 1994; Hady et al., 1994; Kristensen et al., 2006). Although the benefits of regular BCS are intuitive to most dairy producers, nutritionists, and consultants, relatively few dairy farms incorporate it routinely as part of their dairy management strategy (Hady et al., 1994; Schwager-Suter, 1999). One of the major advantages of an automated BCS system would be that it could provide a more objective, consistent measure of BCS than those recorded by human observers. Automated BCS could be incorporated into animal health tracking systems or within integrated monitoring systems (Coffey, 2003). Only a few research groups have approached the idea of automatic BCS of dairy cattle (Coffey et al., 2003a; Leroy et al., 2005; Pompe et al., 2005; Bewley et al., 2008). No automated BCS systems are commercially available but efforts are under way to remedy this void.

The purpose of this paper is to provide a detailed assessment of a dairy investment when a number of underlying factors are uncertain. These uncertainties require special analysis. This paper develops a detailed capital budgeting problem that is linked, via Monte Carlo simulation, to dairy production factors. The paper illustrates the complexity of inter-related production risks affecting projected cash flows which ultimately influence the decision to invest in the technology. Simultaneously, within the simulation market risks are also accounted for within key input and output prices. Finally, this research provides new insight into the factors that influence the profitability of investing in an automated BCS system.

\section{Materials and methods}

A stochastic simulation model of a dairy system, designed to assist dairy producers with investment decisions for PDF technologies, was developed and described in detail in Bewley et al. (2010). The model was constructed in Microsoft Excel 2007 (Microsoft, Seattle, Washington) and incorporated the @Risk 5.0 (Palisade Corporation, Ithaca, New York) add-in to account for the stochastic nature of key variables in the Monte Carlo simulation. As an illustration of model utility, this model was used for an investment analysis of a proposed system for automatically monitoring BCS on dairy farms. For this research example, industry averages for production and financial parameters, selected to represent conditions for a US dairy farm milking 1,000 cows in 2007, as listed in Bewley et al. (2010), were used. If an individual producer were examining this investment decision, he or she could change many of these inputs to match the conditions observed on a specific farm. In order for profitability analysis to be of value in the decision-making process, farm-specific data should be used rather

\section{Dairy cattle body condition scoring system}


AFR 70,1 than assuming average relationships that may not be applicable in all scenarios (Delorenzo and Thomas, 1996; van Asseldonk et al., 1999). Because estimates from the literature were not obtainable for some of the necessary inputs into the model, an expert opinion survey was conducted to fill these voids. Expert opinion can be useful to provide estimates when data have not been previously collected or is too expensive to collect (Vose, 2000). A total of 45 US academic and industry experts were polled who had either published research on BCS or had knowledge of BCS through interactions with producers in extension or consulting activities. Results from this survey were summarized and incorporated into the model.

\section{Body condition score profiles}

In the USA, BCS is conducted subjectively and visually with a 1 (thin) to 5 (fat) scale at 0.25 point intervals (Ferguson et al., 1994). The patterns of BCS change and the associated exchange of energy within lactation play a critical role in dairy cow health, productivity, and efficiency. The distribution of BCS at calving (BCSC) within the herd was established as follows. Experts assessed the percentages of cows within seven $\mathrm{BCSC}$ ranges (1.00-1.75, 2.00-2.25, 2.50-2.75, 3.00-3.25, 3.50-3.75, 4.00-4.25, and 4.50-5.00) for an average dairy herd in 2007 and for dairies incorporating phase feeding with multiple total mixed rations (TMR) and frequent, repeated measurement of BCS (Table I). The ranges for the average herd in 2007 were used to represent a scenario without an automated BCS system (BCSBEF) whereas the ranges for dairies using frequent, repeated measurement of BCS were used to represent a scenario with an automated BCS system (BCSAFT). For each BCSC range, the minimum, mean, and maximum estimate was modeled stochastically using a program evaluation and review technique (PERT) distribution. The PERT distribution is a special case of a scaled beta distribution allowing for skewness using the minimum, mean, and maximum as inputs. The BCSBEF and BCSAFT for each BCSC range among respondents were correlated within the stochastic drawings to ensure that the resulting percentages represented the experts' predicted changes in BCS. The stochastic percentages for each $\mathrm{BCSC}$ were then proportionally adjusted to ensure that the total of the seven $\mathrm{BCSC}$ ranges was 100 percent. Within each $\mathrm{BCSC}$ range, cows were assumed to be distributed equally among possible scores. In other words, if 10 percent of cows were in the 2.50-2.75 range, 5 percent would be scored 2.50, and 5 percent would be scored 2.75. The same distribution of BCS scores was modeled for each of ten years within the simulation.

\section{$B C S$ and disease}

The greatest benefits from managing cows for optimal BCS at each stage of lactation likely come from improvements in animal health (Waltner et al., 1993). However, in published research, the association between absolute BCS or changes in BCS with health disorders has been variable (Ferguson, 2002). A major limitation with much of the research designed to examine the impact of varying BCS is a lack of animals in the more extreme condition score ranges (Waltner et al., 1993; Broster and Broster, 1998). The most consistent relationship among published studies has been the increased incidence of ketosis for cows with higher BCSC (Ferguson, 2002). The relationship between BCS and metritis and milk fever has been moderately consistent, whereas relationships between BCS and retained placenta, displaced abomasum, cystic ovaries, dystocia, mastitis, and lameness have been more variable. 


\begin{tabular}{|c|c|c|c|c|c|c|}
\hline \multirow[b]{2}{*}{$\mathrm{BCS}$ range } & \multicolumn{3}{|c|}{ All respondents $(n=24)$} & \multicolumn{3}{|c|}{ Selected respondents ${ }^{\mathrm{a}}(n=5)$} \\
\hline & Minimum & Mean & Maximum & Minimum & Mean & Maximun \\
\hline \multicolumn{7}{|c|}{ Percentage of cows on a typical dairy within BCS ranges } \\
\hline $1.00-1.75$ & 0.00 & 1.61 & 5.00 & 0.50 & 2.10 & 5.00 \\
\hline $2.00-2.25$ & 0.00 & 6.09 & 15.00 & 2.00 & 7.40 & 10.00 \\
\hline $2.50-2.75$ & 0.00 & 22.26 & 42.00 & 7.00 & 29.40 & 40.00 \\
\hline $3.00-3.25$ & 10.00 & 36.57 & 80.00 & 30.00 & 44.20 & 80.00 \\
\hline $3.50-3.75$ & 5.00 & 22.74 & 50.00 & 5.00 & 12.40 & 25.00 \\
\hline $4.00-4.25$ & 0.00 & 8.13 & 20.00 & 2.00 & 3.80 & 5.00 \\
\hline $4.50-5.00$ & 0.00 & 2.24 & 10.00 & 0.00 & 0.70 & 2.00 \\
\hline \multicolumn{7}{|c|}{ Percentage of cows within BCS ranges under optimal nutritional management } \\
\hline $1.00-1.75$ & 0.00 & 0.38 & 5.00 & 0.00 & 1.20 & 5.00 \\
\hline $2.00-2.25$ & 0.00 & 2.42 & 10.00 & 0.00 & 4.80 & 10.00 \\
\hline $2.50-2.75$ & 0.00 & 18.96 & 60.00 & 5.00 & 38.00 & 60.00 \\
\hline $3.00-3.25$ & 0.00 & 42.63 & 90.00 & 25.00 & 48.00 & 90.00 \\
\hline $3.50-3.75$ & 4.00 & 29.83 & 75.00 & 4.00 & 6.80 & 10.00 \\
\hline $4.00-4.25$ & 0.00 & 4.83 & 25.00 & 0.00 & 1.20 & 5.00 \\
\hline $4.50-5.00$ & 0.00 & 0.92 & 5.00 & 0.00 & 0.00 & 0.00 \\
\hline
\end{tabular}

Notes: Of 45 experts surveyed, 24 were returned and used; ${ }^{\text {a }}$ selected respondents were those in the 80th percentile for percentage of cows with $\mathrm{BCS} \leq 3.25$ under optimal nutritional management Dairy cattle
body condition
scoring system

129

Table I.

Minimum, mean, and maximum estimates for percentage of cows within BCS ranges obtained from expert opinion survey

In this model, the effects of varying BCSC on disease incidence were modeled using estimates for varying odds ratios associated with different levels of BCSC obtained from literature (Table II). For each disease, the reported means and 95 percent confidence intervals for each score were modeled stochastically within PERT distributions to provide an odds ratio for each BCS category. The default (or user input) disease incidence rate and $\mathrm{BCSBEF}$ distribution were combined to calculate a base disease risk for the reference $\mathrm{BCSC}$ range. The reference $\mathrm{BCSC}$ ranges for ketosis, milk fever, and metritis were 3.00-3.25, 3.00, and $>2.00$, respectively. For a simplified example of the calculation of the base disease risk for ketosis, let's assume that 50 percent of the cows have BCSC from 3.00 to 3.25 and 50 percent from 3.50 to 3.75 and that the default overall herd incidence of ketosis was 5 percent. With this knowledge, we were still left with the dilemma of determining the incidence rate for each BCSC category. The odds ratio for BCSC 3.50-3.75 was 2.4 indicating that cows in this score range were 2.4 times more likely to have ketosis than cows in the reference category $(\mathrm{BCSC}=3.00-3.25)$. Algebraically, we can determine that a ketosis incidence rate of 2.94 percent for cows with BCSC 3.00-3.25 and 7.05 percent for cows with BCS 3.50-3.75 would result in an overall herd ketosis incidence rate of 5 percent. In this manner, we took into account that even cows with a BCSC closer to ideal were still at some risk for each disease. As the percentage of cows calving in the reference BCSC range increased, the risk of each disease will decrease accordingly.

The BCSBEF and BCSAFT were used to calculate different incidence rates for ketosis, milk fever, and metritis for the two different scenarios with and without the automated BCS technology. Theoretically, an automated BCS system could provide information to the dairy producer that would be used to better manage $\mathrm{BCSC}$ resulting in more cows calving within recommended BCS ranges. In turn, the disease incidence rates would decrease. The economic implications of changes in incidence rates were modeled within the disease modules (retention pay-off, disease incidence, culling, 


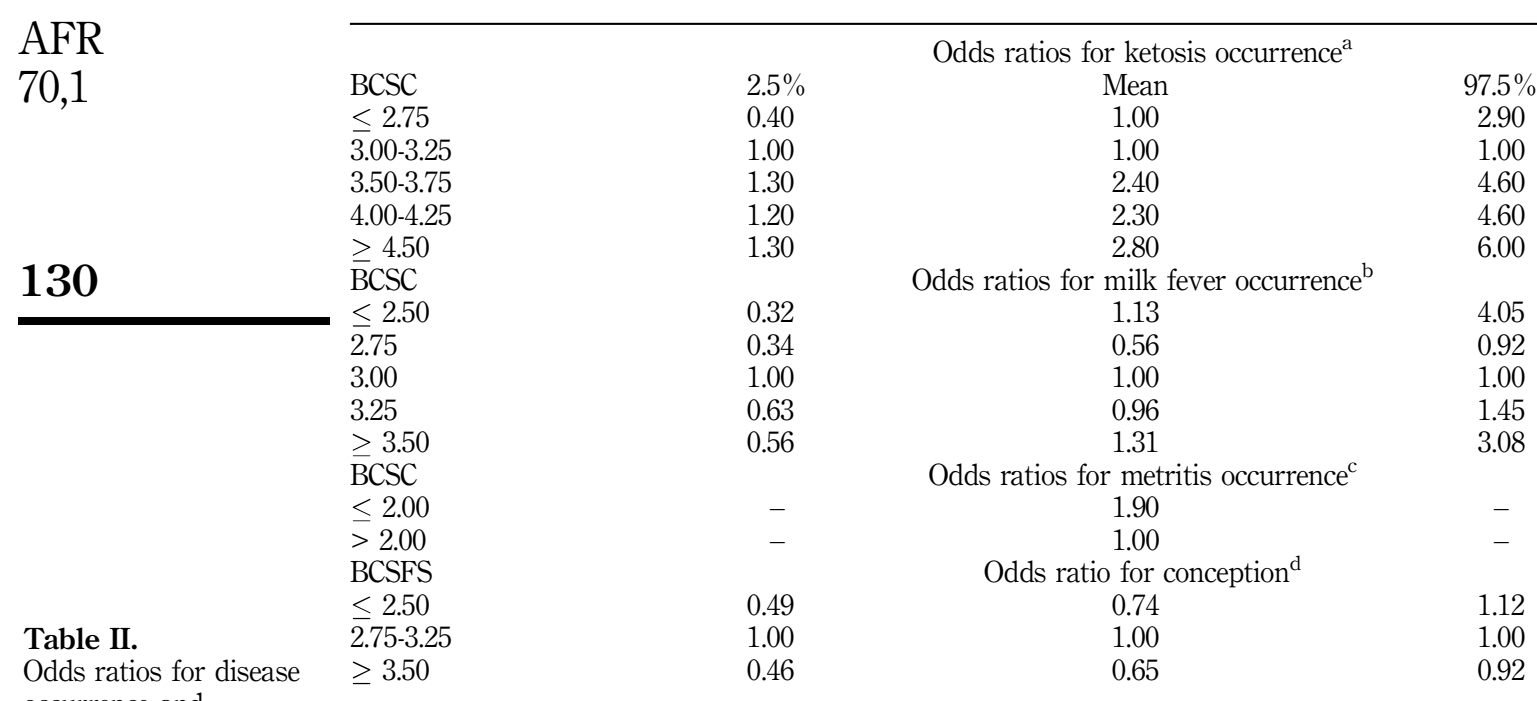

occurrence and conception rate at first service with varying $\mathrm{BCS}$
Notes: 2.5 percentile, mean, and 97.5 percentile modeled stochastically within a PERT distribution

Sources: ${ }^{\text {a}}$ From Gillund et al. (2001); ' from Roche and Berry (2006); ' from Heuer et al. (1999); ${ }^{\text {dfrom }}$ Loeffler et al. (1999)

disease milk loss, and other disease costs) as described in Bewley et al. (2010). The RiskData function of @Risk was used to calculate the difference in the disease costs between the two scenarios with and without the technology and results were transferred to the revenues and expenses module where they were used for the investment analysis.

\section{$B C S$ and reproduction}

Fertility of dairy cows is retarded by negative energy balance during early lactation which increases the time to first ovulation, reduces conception rates, and impacts early embryonic development. As with health, responses to varying BCS on reproduction have varied considerably within the literature (Broster and Broster, 1998). Decreased reproductive performance has been more closely related to low BCS at first insemination or increased BCS loss than with BCSC (Ferguson, 2002). Reproductive performance is decreased at both ends of the BCS scale with problems observed for both extremely thin and extremely fat cows. One of the few studies to quantify a difference in reproductive performance in both fat and thin cows within the same study was conducted in the Netherlands (Loeffler et al., 1999). The reduced odds for conception at first service reported in their work (Table II) were incorporated into this model to reflect changes in reproductive performance associated with $\mathrm{BCS}$. The conception rate for the reference category (BCS 2.75-3.25) was calculated using the same methodology as described for disease incidence. Then, a first service conception rate was calculated for BCSBEF and BCSAFT using the respective distributions. The overall conception rate was adjusted correspondingly with the first service conception rate adjusted for BCS and the conception rates for subsequent services remaining at their base levels. This BCS-adjusted conception rate was then utilized in calculations for predicted days open (DO), costs of $\mathrm{DO}$, and other reproductive parameters in the 
reproduction module as described in Bewley et al. (2010). The changes in total DO resulting from changes in disease incidence were also calculated in this module. The difference in reproductive losses resulting from varying DO between BCSBEF and BCSAFT was calculated and transferred to the revenues and expenses module for use within the investment analysis.

\section{Energy efficiency}

All cows have a genetically programmed target BCS that they will attempt to attain at ten to 12 weeks post-calving (BCSTAR) (Friggens et al., 2004; Garnsworthy, 2007). For each BCSC, the predicted BCSTAR was calculated as described in Bewley et al. (2010). Assuming a linear change in BCS, the BCS at first service (BCSFS) was calculated as the midpoint between BCSC and BCSTAR. The default day of BCSTAR was 112 days in milk (DIM); thus, the predicted DIM at BCSFS was 56. The average BCSC, BCSTAR, and BCSFS during each year of the simulation was calculated as a weighted average using the percentages of cows in each BCS range. The difference between BCSC and BCSTAR represents the early lactation change in BCS. The average BCS at these key points within the lactation were then used to model the daily change in $\mathrm{BCS}$, using the methodology of Friggens et al., (2004) which was described in detail in Bewley et al. (2010). Ultimately, the average cow in the herd during each year of the simulation was assumed to begin each lactation at the weighted average BCSC, decrease BCS until she reaches BCSTAR, and increase BCS until the beginning of the subsequent lactation. Using a herd-based average cow model structure, an assumption was made that, at a herd level, the higher BCS loss by extremely fat cows was negated by the BCS gain by extremely thin cows.

The dairy cow is more efficient at turning energy from feed into milk than she is at turning energy from body reserves into milk. Thus, a constant cycle of using energy reserves in early lactation for milk production then recuperating these reserves in late lactation is biologically inefficient. As the magnitude of body reserves lost in early lactation increases, biological and economical inefficiency also increases. Varying BCS profiles may have economic consequences through differences in energy efficiency. Consequently, one of the major considerations in this economic analysis was to quantify the economic impact of varying BCS profiles.

The approach to calculating the costs of this energy exchange was partially based upon the methodology described by Wall et al. (2008). The first step in calculating changes in energy reserves was to convert the daily BCS scores to live body weight in $\mathrm{kg}$ (LBW). The change in LBW from change in BCS was calculated with the assumption that the mean change in LBW per one-unit change (on the five-point scale) in BCS was 13.7 percent as described in the NRC (2001). Empty body weight (EBW) was then calculated by multiplying LBW by 0.817 (NRC, 2001). The equations for describing the relationship between BCS and body composition were based on a ninepoint BCS scale (BCS9). Therefore, the daily BCS were converted to a BCS9 scale with the following equation for these calculations (NRC, 2001):

$$
\mathrm{BCS} 9=((\mathrm{BCS}-1) \times 2)+1,
$$

where BCS9 is BCS on a nine-point scale and BCS is BCS on a five-point scale.

The equations for calculating the daily level of empty body fat and protein, respectively, were:

\section{Dairy cattle body condition scoring system}


where EBF is empty body fat in kg, BCS9 is BCS on a nine-point scale, and EBW is empty body weight in $\mathrm{kg}$.

$$
\mathrm{EBP}=(0.200886-(0.0066762 \times \mathrm{BCS} 9)) \times \mathrm{EBW},
$$

where $\mathrm{EBP}$ is empty body protein in $\mathrm{kg}, \mathrm{BCS} 9$ is $\mathrm{BCS}$ on a nine-point scale, and $\mathrm{EBW}$ is empty body weight in $\mathrm{kg}$. 2006):

The predicted daily energy content was then calculated as follows (Banos et al.,

$$
\mathrm{EC}=((9.4 \times \mathrm{EBF})+(5.7 \times \mathrm{EBP})) \times 4.1868,
$$

where $\mathrm{EC}$ is daily energy content in $\mathrm{MJ}, \mathrm{EBF}$ is empty body fat in $\mathrm{kg}$, and $\mathrm{EBP}$ is empty body protein in $\mathrm{kg}$.

Daily changes in EBF and EBP were calculated as the difference between total EBF and EBP on successive days. In turn, these changes were used to calculate effective energy balance as described by Banos et al. (2006). Estimates for the amount of energy used when lipid and protein weights changed were based on the work of Emmans (1994). For each $1 \mathrm{~kg}$ of lipid or protein gain, 56 and 50 MJ of energy are needed, respectively. When $1 \mathrm{~kg}$ of lipid or protein is lost, 39.6 and $13.5 \mathrm{MJ}$ of protein are released. These estimates were combined with the daily change in EBF and EBP to compute the MJ of energy released or gained each day. Then, the daily net energy balance was calculated as the sum of the MJ of energy and protein released or gained. The deterministic corn price for each year, obtained from estimates from the Food and Agricultural Policy Research Institute's (FAPRI) USA and World Agricultural Outlook Report (FAPRI, 2007) was used as a proxy for the cost of energy per MJ. When the daily net energy balance was negative, indicating that the animal was using body reserves to meet her energy and protein requirements, the cost of energy per MJ was multiplied by the net energy balance to provide an estimate of cost savings. Conversely, when the daily net energy balance was positive, indicating that the animal was using consumed energy to replenish or supplement energy and protein reserves, the cost of energy per MJ was multiplied by the net energy balance to provide an estimate of the cost of adding to body reserves.

The cumulative costs of energy exchange were summed for the average cow in each of six parity groups (1-5 and $\geq 6$ ). Theoretically, if a cow maintained the same BCS throughout lactation, the cumulative costs of energy exchange would be $\$ 0$. For most cows, however, some BCS loss in early lactation will occur. Most mammals are biologically designed to use energy reserves during early lactation as an evolutionary mechanism to protect offspring. Nevertheless, there is an economic cost associated with this loss because the cow is more efficient at utilizing energy from feed than from body reserves. At some level, this cost is unavoidable. Rather, the objective should be to minimize the economic costs of energy exchange within the lactation by avoiding cows that mobilize excessive amounts of BCS. For example, the costs of energy exchange would be much greater for a cow with BCSC of 4.00 that drops to a BCSTAR of 3.25 than for a cow with BCSC of 3.25 that drops to a BSCTAR of 3.00 .

The cumulative costs of energy exchange for the average cow in each parity group were multiplied by the number of cows calving within the respective parity group 
during the given year to obtain a total cost of energy exchange for the herd for each year. This calculation was made for two different scenarios using BCSBEF (representing a scenario without adopting the automated BCS system) and BCSAFT (representing a scenario having adopted the automated BCS system). The RiskData function of @Risk was used to calculate the differences between these two values and this result was transferred to the revenues and expenses module.

Technology considerations

Assumptions for analyzing an investment in an automated BCS system are listed in Table III. The investment costs and maintenance fees were projected prices provided by a company currently developing an automated BCS system (Boyce, 2007, personal communication). The labor costs involved with analyzing data provided by the BCS system were considered with the assumption that $0.5 \mathrm{~h}$ per week would be spent analyzing data. These costs were multiplied by labor costs to provide an annual labor cost. An assumption was made that the dairy was feeding multiple TMR with rations tailored to meet the specific nutritional needs of cows at varying lactation stages. If a dairy feeds a single TMR to the entire milking herd, they would not benefit from the information provided by an automated BCS system. After investing in an automated BCS technology, additional costs will likely be incurred for management or nutritional changes necessary to observe the optimal BCS levels indicated by experts. For example, it may be necessary to include new feed additives or alter rations which could increase feed costs or additional labor or equipment maintenance may be needed for ration delivery. To account for these additional costs, an annual charge for incremental, per cow, variable costs was modeled stochastically using a PERT distribution.

\section{Investment analysis}

Each of the calculations above provided essential information for the investment analysis. Using a partial budget approach, all predicted revenues and expenses resulting from investing in an automated BCS system over the ten-year investment period were collected. Revenues were divided into eight savings categories based on the differences between the two scenarios using BCSBEF and BCSAFT: culling, death, veterinary and drug, labor, discarded milk, unrealized milk gain, reproduction, and energy efficiency. Annual expenses included maintenance fees, labor costs for

\begin{tabular}{lcl}
\hline Parameter & Estimate & Reference \\
\hline Initial investment $(\$)$ & 12,000 & Boyce (2007, personal communication) \\
Annual maintenance fee $(\$)$ & 1,200 & Boyce (2007, personal communication) \\
Miscellaneous setup costs $(\$)$ & 500 & Model input \\
Equipment salvage value $(\$)$ & 0 & Boyce (2007, personal communication) \\
Equipment useful life, years & 10 & Boyce (2007, personal communication) \\
Depreciate period, years & 5 & Model input \\
Time spent analyzing data, & 0.5 & Model input \\
hours per week & & Model input \\
Incremental annual variable & $0.0,2.5,5.0^{\mathrm{a}}$ & \\
costs, per cow $(\$)$ &
\end{tabular}

Note: ${ }^{a}$ Minimum, mean, and maximum values modeled within a PERT distribution

\section{Dairy cattle body condition scoring system}

Table III.

Investment considerations for an automated BCS system 
AFR 70,1

analyzing data, and increased variable costs for management changes needed to obtain optimal BCS.

A best management practice adherence factor (BMPAF) as described in Bewley et al. (2010) was used to proxy the potential of actually achieving the optimal BCS after investment in an automated BCS system. The BMPAF was a crude scale from 1-100 percent designed to represent the level of farm management. In this example, the default level was set at 77 percent. Practically, the BMPAF was modeled by simply multiplying the revenues modeled to this point by the BMPAF, reducing the potential revenues from the technology accordingly.

The net present value (NPV) was the metric used to assess the profitability of the investment. The asset approach was used to calculate the discount rate, whereby the outlay is the total capital investment; the discount rate reflects the optimal debt/equity capital structure and the cash flows therefore do not include principal and interest payments on debt obligations. The discount rate of 8 percent was adjusted to 10 percent because this technology has not been marketed commercially; thus, the risk for early adopters of the technology is higher. The discount rate partially accounts for this increased risk by requiring higher returns from the investment. The general rule of thumb is that a decision with a NPV greater than 0 is a "go" decision and a worthwhile investment for the business. The investment at the beginning of the project includes the purchase costs of the equipment needed to run the system in addition to purchasing any other setup costs or purchases required to start the system. Investments were depreciated using straight-line depreciation over a five-year period. Taxes were calculated using the 35 percent tax rate input in Module one. Net cash flows were collected and adjusted by their respective discount rates. Finally, the NPV was calculated by collecting the discounted cash flows. The NPV was calculated with the following formula (Boehlje and Ehmke, 2005):

$$
\mathrm{NPV}=\sum_{n=1}^{K} \frac{I_{n}}{(1+d)^{n}}-O,
$$

where NPV is net present value, $n$ is time period, $K$ is the last period an inflow is expected, $I_{n}$ is the net cash inflow in period $n, d$ is the discount rate, and $O$ is the cash outlay required to purchase the asset.

In addition to the profitability of the investment, the decision maker should also be concerned about the financial feasibility of the project. This module determines if the project will cash flow. The amount of the loan (equal payments) was calculated with a 0 percent down payment over the ten-year period of the project using the interest rate provided by the user. The payment schedule was adjusted to an after-tax basis so as to be comparable to the after tax cash income available for debt servicing. Annual net cash flows were compared to after-tax annual principal and interest payments to determine if a cash surplus or deficit will occur.

\section{Stochastic simulation}

Recognizing that a deterministic model ignores the uncertainty inherent in a dairy system, Monte Carlo simulation was conducted using the @Risk add-in. This type of simulation provides infinite opportunities for sensitivity analyses. Sensitivity analyses, designed to evaluate the range of potential responses, provides further insight into an investment analysis (van Asseldonk et al., 1999). In each simulation, 
Latin Hypercube sampling was used with a fixed seed of 31,517 to ensure all simulations provided repeatable results. Three full simulations were run using 1,000 iterations in each simulation. One simulation (ALLSIM) was run using the BCSBEF and BCSAFT provided by all 24 experts who answered the expert opinion survey. However, in general, the experts indicated a higher BCSC under optimal nutritional management (more cows with BCSC of 3.50-3.75) than the research data chosen for this model would suggest was optimal (Heuer et al., 1999; Loeffler et al., 1999; Gillund et al., 2001; Roche and Berry, 2006). For example, Heuer et al. (1999) showed that cows with BCSC of 3.50-3.75 were 2.4 times more likely to experience ketosis than cows with BCSC of 3.00-3.25; and Loeffler et al. (1999) demonstrated that the odds for conception for cows with BCSFS $\geq 3.50$ were lower (0.65) than for cows with BCSFS 2.75-3.25. As a result, a second simulation (LOWSIM) was run to assess how the results would change with a lower optimal BCSC (fewer cows with BCSC of 3.50-3.75), as supported by recent literature (Heuer et al., 1999; Loeffler et al., 1999; Gillund et al., 2001; Roche and Berry, 2006). To accomplish this, survey respondents were sorted, from lowest to highest, by the projected percentage of cows with $\mathrm{BCSC} \leq 3.25$ under optimal management. Then, estimated BCSBEF and BCSAFT from respondents in the 80th percentile $(n=5)$ for this percentage were utilized within the simulation. Lastly, a third simulation was run with deterministic distributions for BCSBEF and BCSAFT (DETSIM). In this simulation, the mean BCS of all 24 experts was used for BCSBEF and the mean BCS for respondents in the 80th percentile $(n=5)$ for the percentage of cows with $\mathrm{BCSC} \leq 3.25$ were used for BCSAFT. A final sensitivity analysis was performed for six potentially influential deterministic inputs (number of cows, BMPAF, rolling herd average milk production, ketosis incidence, purchase price, and base culling rate). For each influential deterministic input, 100 iterations were run at both extreme minimum and maximum values.

\section{Results and discussion}

As is often the case when examining new technologies, published estimates for the impact of an automated BCS system were not available. Though the BCS literature is expansive, the economic aspects of this technique have not been explored. Thus, a methodology to examine the potential benefits and risks from an automated BCS system is needed. Lastly, this type of feasibility analysis can be beneficial for technology manufacturers in prioritizing allocation of limited research and development funds and in setting pricing policies for new technologies.

\section{Body condition score ranges}

In Table I, expert responses for the percentage of cows on a typical dairy falling within BCS ranges along with obtainable ranges under optimal management are summarized. Among the 24 survey respondents, 15 were nutritionists, five were veterinarians, three were geneticists, and one was a reproductive physiologist. Fifteen respondents were in academia while nine were in industry. Examining the means for all respondents $(n=24)$, these experts indicated that, with optimal nutritional management, the proportion of cows with BCSC in the 1.00-1.75, 2.00-2.25, 2.50-2.75, 4.00-4.25, and 4.505.00 ranges would decrease. Conversely, the proportion of cows in the BCSC ranges of 3.00-3.25 and 3.50-3.75 would increase. Thus, these experts clearly indicated that frequent BCS can provide useful information that can be used in nutritional management to reduce the number of excessively thin or fat animals. It can be inferred from this data that these experts believed that either the optimal BCSC ranges from

\section{Dairy cattle body condition scoring system}

135 
AFR 70,1

2.50 to 3.75 or that, in efforts to attain a moderate BCSC, these proportions are the best that could actually be observed.

Comparing these results with the odds ratios for diseases and conception rates listed in Table II, one can easily see that the predicted increase in the percentage of cows with BCSC of 3.50-3.75 may be problematic. Using the mean changes in BCSC distributions from the expert opinion survey in a model with these odds ratios will result in a prediction of increased incidence of ketosis and milk fever and reduced conception rates at first insemination. A paradox arises in that "optimal nutritional management" would appear to result in increased health and reproductive problems. This likely indicates one of the following issues:

- the experts' opinions of optimal BCSC is higher than the true optimal BCSC;

- the experts misinterpreted the questions being asked;

- the experts may have different interpretations of BCS characterizations particularly in the middle of the range;

- the decision to include ranges of BCS scores rather than all 17 points on the BCS scale within the survey restricted flexibility in answering the questions;

- the experts believe that even if one manages for a lower optimal score, there will still be a portion of cows with BCSC of 3.50-3.75;

- the research studies chosen for modeling of disease and reproduction do not reflect reality; or

- higher BCS are recommended for reasons other than health and reproduction.

So, this begs the question "What is the ideal BCS?" The ideal BCS is the level of body fat that allows the cow to maximize milk production while simultaneously minimizing metabolic and reproductive disorders (Perkins et al., 1985; Spain, 1996). In reality, the ideal level of BCS loss is unknown and highly dependent on the production system in which cows are managed (Coffey et al., 2004). Contreras et al. (2004) suggested that cows with lower BCS (2.75-3.00) at dry-off outperform those with higher BCS with modern transition cow management programs in place. Busato et al. (2002) proposed that farmers strive for a BCS around 3.25 during the dry period and for $<0.75$ units of loss during the first two months of lactation. Ferguson (2001) indicated that decreased fertility begins when cows lose $>0.67$ units of BCS during early lactation. Chagas $e t a l$. (2007) presented the "ideal BCS profile with focus on minimizing the effects of negative energy balance on reproduction. In their profile, the suggested range for BCS at calving is 3.00 to 3.50 with a nadir of 2.50 to 3.00 and scores increasing progressively through the remainder of lactation."

The research studies chosen to represent odds ratios for disease and conception rates were chosen after an extensive review of the literature because they were recent studies that quantified changes associated with varying BCS that could be modeled. It is important to note that they were limited because they may represent conditions specific to their respective study, some were performed outside of the USA, the ranges chosen for comparison within each study may have impacted results, and BCS is a subjective technique. Given the subjective nature of BCS, it is doubtful that the difference between a BCSC of 3.25 and 3.50 is as dramatic as these studies would suggest. Nevertheless, these were the best estimates that we could obtain. Further, to the knowledge of the authors, there is no evidence supporting an ideal BCSC above 3.50. In conclusion, it is possible that industry recommendations for BCSC may be 
higher than ideal. Additional epidemiological efforts should be undertaken to better define the differences in disease incidence associated with varying BCS. To examine the economic impact of striving for a lower ideal BCSC, responses were categorized by the percentage of cows with $\mathrm{BCSC} \leq 3.25$ under optimal nutritional management. Results for the top 20 percent $(n=5)$ were summarized (Table I) and a separate simulation was run using these results.

Other survey responses

Experts were also asked to rank the potential benefits of automated BCS (Table IV). Only responses with all six possible ratings were included in the analysis $(n=21)$. Survey respondents viewed disease reduction as the most important potential benefit with 50 percent of respondents ranking this as the top benefit. Using the mean rating (lowest to highest) as the ranking criteria disease reduction was followed in importance by nutritional cohort management, reproduction, animal well-being, energy efficiency, and genetics. In general, the experts surveyed did not view genetics as a potential benefit with 63.64 percent of respondents ranking this as the least important benefit. Genetic studies have clearly demonstrated that differences between the condition score curves among different sires exist (Jones et al., 1999; Coffey et al., 2003b; Wall et al., 2007). Because most of the experts surveyed were nutritionists, this may indicate unfamiliarity with this research. On the other hand, it may reflect that a producer who adopts an automated BCS system would not benefit from the added value of including $\mathrm{BCS}$ in genetic evaluations any more than a non-adopter would. For the question "what percentage of producers would you estimate incorporate repeated, scheduled BCS into their management routines and nutritional management," the mean response was 24.23 percent $\pm 21.90(n=23)$. The high standard deviation (SD) for these responses indicates that there was considerable disagreement likely reflective of different interpretations of the questions or geographic and size differences among the herds with which the experts work. When asked "what percentage of producers would you estimate feed multiple TMR for lactating cows based upon specific nutrient requirements," the mean response was 36.48 percent $\pm 19.33(n=23)$. Assuming this percentage was reasonably accurate; this represents a potential barrier to adoption of automated BCS. Without feeding multiple TMR, the benefits of BCS are reduced

\begin{tabular}{|c|c|c|c|c|c|c|c|c|}
\hline $\begin{array}{l}\text { Benefit of } \\
\text { automated } \\
\text { BCS }\end{array}$ & $\begin{array}{l}\text { Mean } \\
\text { rating }\end{array}$ & $\begin{array}{l}\text { SD } \\
\text { of } \\
\text { rating }\end{array}$ & $\begin{array}{c}\text { Percentage } \\
\text { rating } 1 \\
(\%)\end{array}$ & $\begin{array}{c}\text { Percentage } \\
\text { rating } 2 \\
(\%)\end{array}$ & $\begin{array}{l}\text { Percentage } \\
\text { rating } 3 \\
(\%)\end{array}$ & $\begin{array}{c}\text { Percentage } \\
\text { rating } 4 \\
(\%)\end{array}$ & $\begin{array}{c}\text { Percentage } \\
\text { rating } 5 \\
(\%)\end{array}$ & $\begin{array}{c}\text { Percentage } \\
\text { rating } 6 \\
(\%)\end{array}$ \\
\hline $\begin{array}{l}\text { Disease } \\
\text { reduction }\end{array}$ & 1.86 & 1.04 & 50.0 & 2 & 18.18 & 9.09 & 0.00 & 0.00 \\
\hline $\begin{array}{l}\text { Cohort } \\
\text { management }\end{array}$ & 2.95 & 1.40 & 13.64 & 31.82 & 18.18 & 22.73 & 9.09 & 4.55 \\
\hline eproduction & 3.09 & 1.41 & 13.6 & 2 & 27. & & 13. & 4.55 \\
\hline $\begin{array}{l}\text { Animal } \\
\text { well-being }\end{array}$ & 3.68 & 1.52 & 9.09 & 13.64 & 22.73 & 22.73 & 18.18 & 13.64 \\
\hline Energy & 4.09 & 1.57 & 13.64 & 4.55 & 4.55 & 27.27 & 36.36 & 13.64 \\
\hline Genetics & 5.32 & 1.17 & 0.00 & 4.55 & 9.09 & 0.00 & 22.73 & 63.64 \\
\hline
\end{tabular}

Note: Rankings were ordered on a scale from $1-6$ with 1 as the highest ranking and 6 as the lowest ranking

\section{Dairy cattle body condition scoring system}


AFR 70,1

dramatically. Dividing cows into multiple groups, based upon BCS, provides the opportunity to deliver targeted rations to groups of animals, designed to more closely meet the nutritional needs of each group. In practice, many dairy producers maintain a single TMR, feeding the same TMR to every cow in the milking herd. The logic provided for this strategy focuses primarily on convenience and cost. Relatively few producers group cows based on BCS, although this strategy has been heavily promoted (Braun et al., 1987; Upham, 1990).

\section{Simulation results}

Simulated annual expenses, associated with investing in the technology, ranged from less than $\$ 3,000$ per year to almost $\$ 7,000$ a year for both ALLSIM and LOWSIM. The majority of the variation was derived from the stochastic increases in variable costs. If simulated variable costs were low, annual expenses were also low while high variable costs were associated with higher annual expenses. Differences among years were caused by changes in herd size which has a small impact on these variable costs. Simulated annual revenues varied from $-\$ 4,000$ to approximately $\$ 10,000$ for the simulation using all respondents and from $\$ 2,000$ to approximately $\$ 12,000$ for the simulation using BCS distributions from respondents in the 80th percentile for percentage of cows with $\mathrm{BCS} \leq 3.25$ under optimal nutritional management. Mean revenues for LOWSIM were generally higher than mean revenues for ALLSIM. This occurs because the range of responses from the LOWSIM respondents generally predicted a decrease in the number of cows with $\mathrm{BCSC}>3.25$. As a result, the disease incidence for BCSAFT would tend to be lower, conception rates would be higher, and the losses from energy exchange would be lower for these thinner cows. On the other hand, the SD for revenue categories were generally higher for ALLSIM than for LOWSIM indicating more upside risk in this simulation. The scenarios with higher revenues were those for which the percentage of cows with $\mathrm{BCSC} \geq 3.50$ was considerably higher for BCSBEF than for BCSAFT. In these cases, disease incidence would be decreased, conception rates improved, and costs of energy exchange reduced. For both ALLSIM and LOWSIM, the mean and SD of cost of culling varied considerably from other years. This result occurs because of adjustments made to herd size in a few simulations which alters the distribution for costs of culling.

The distributions of average annual revenues among revenue categories are presented in Figure 1. In both simulations, the primary source of revenues was improvements in reproductive performance. Reproductive performance was improved by changes in conception rates at first service associated with varying BCSFS and through reductions in DO from reduced disease incidence. Reproductive efficiency is a primary determinant of productivity and profitability on dairy operations (Skidmore, 1990). In this example, it was easy to see how even small changes in reproductive performance can have a dramatic economic impact. For LOWSIM, 14.5 percent of the revenues were derived from improvements in energy efficiency resulting from fewer cows mobilizing excessive reserves in early lactation. With lower BCS, cows do not waste as much energy going through the inefficient process of depleting and replenishing high levels of body reserves each year. Surprisingly, the revenues obtained from reduced disease incidence were relatively small in comparison to reproduction and energy efficiency. This was contradictory to the experts' assessment of disease reduction as the most important benefit of automated BCS. For ALLSIM, on average, the model predicted an increase in disease incidence and costs because of the increased percentage of cows with BCSC 3.50-3.75, which explains the low means 
observed for revenues from reductions in disease costs. However, considering the large SD for these revenues, the model predicted large gains from reduced disease incidence for those iterations where the percentage of cow with BCS $>3.25$ was decreased. For LOWSIM, on average, revenues from reductions in disease costs were consistently low. Looking at BCSBEF and BCSAFT in Table I again, we can see that although these experts suggested an optimal BCSC range more aligned with the disease and conception rate odds ratio here, they also indicated that $\mathrm{BCSC}$ for the average herd were already close to the ideal. Thus, using these distributions in the model will only result in slight reductions in disease incidence.

(a)

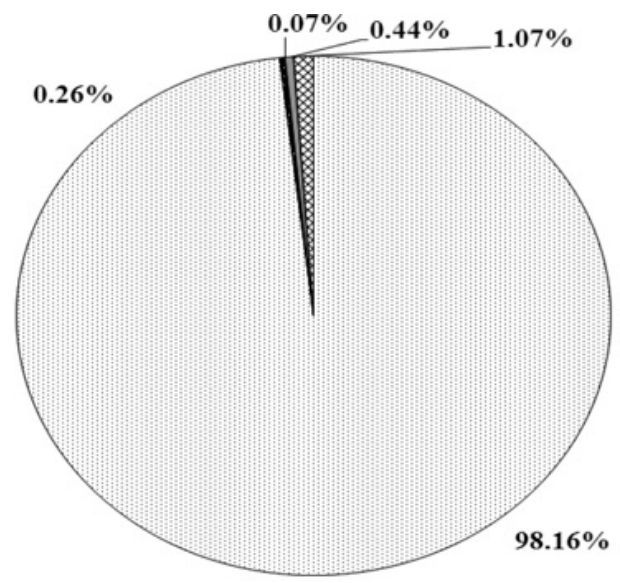

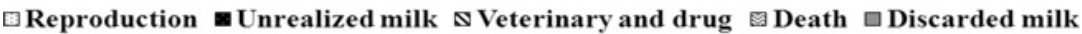

(b)

Notes: (a) All respondents and (b) selected respondents; selected respondents $(n=5)$ indicated a lower percentage of cows with BCS $\leq 3.25$ after technology adoption

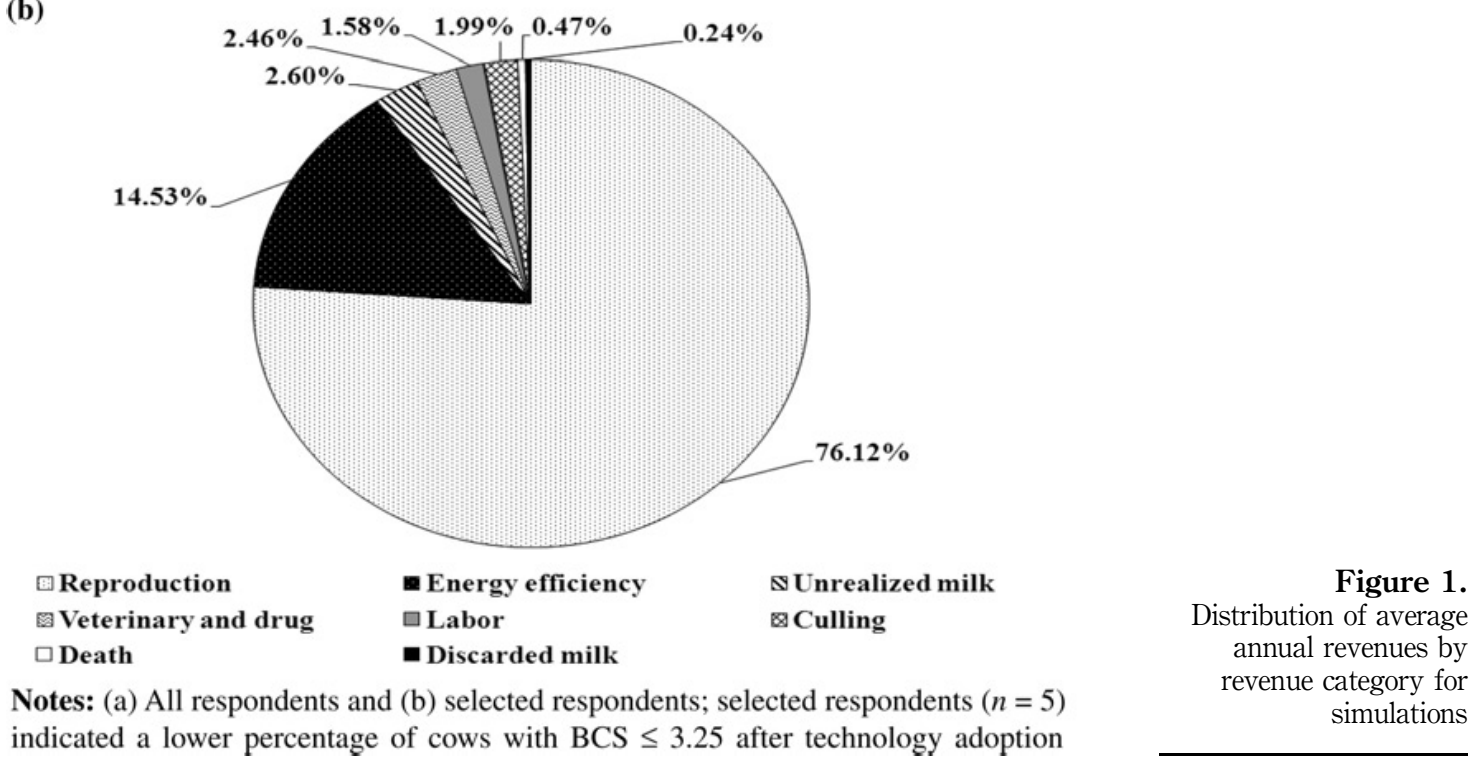

Dairy cattle body condition scoring system 
AFR 70,1

The difference between revenues and expenses provides the information needed to calculate the financial feasibility of the investment. Cash flows ranged from a deficit of approximately $\$ 11,000$ to a surplus of almost $\$ 4,000$ for ALLSIM and from a deficit of approximately $\$ 5,000$ to a surplus of almost $\$ 6,000$. The mean cash flows were negative for ALLSIM and about break-even for LOWSIM. This result indicates that even if the project was profitable, it was not financially feasible. In reality, for an investment this small in a herd this large, financial feasibility may not be a major decision-making criterion.

\section{Profitability analysis}

Cumulative distribution functions (CDF) of NPV for ALLSIM and LOWSIM are presented in Figure 2. CDF of NPV for simulation modeling a deterministic 25 percent decrease in the percentage of cows with $\mathrm{BCSC} \leq 3.25$ are shown in Figure 3. For ALLSIM, 12.6 percent of simulation iterations resulted in a positive NPV whereas this same number was 38.7 percent for LOWSIM. In other words, using the model assumptions described here for an average 1,000 cow US dairy in 2007, investing in an automated BCS system was the right decision 12.6 and 38.7 percent of the time for ALLSIM and LOWSIM, respectively. The individual decision maker's level of risk aversion would then determine whether they should make the investment. Though the chances of obtaining a positive NPV were higher for LOWSIM than ALLSIM, in both cases this would indicate that investing in this system would be risky for most producers. The chances of a positive NPV were considerably higher for DETSIM where the percentage of cows with BCS $\leq 3.25$ decreased by 25 percent in all iterations. In this simulation, the decision to invest in an automated BCS system was the right decision 86.6 percent of the time. Although this serves as an example of how this model could be used for an individual decision maker, this profitability analysis should not be taken literally. In reality, an individual dairy producer would need to look at this decision using herd-specific variables to assess the investment potential of the technology. The main take home message from these figures was that because results from the investment analysis were highly variable, this technology is certainly not a "one size fits all" technology that would prove beneficial for all dairy producers.

\section{Sensitivity analyses}

The primary objective of this research was to gain a better understanding of the factors that would influence the profitability of investing in an automated BCS system through sensitivity analysis. Sensitivity analysis, designed to evaluate the range of potential responses, provides further insight into an investment analysis (van Asseldonk et al., 1999). In sensitivity analyses, tornado diagrams visually portray the effect of either deterministic or stochastic variables on an output of interest. In a tornado diagram, the lengths of the bars are representative of the sensitivity of the output to each input. The tornado diagram is arranged with the most sensitive input at the top progressing toward the least sensitive input at the bottom. In this manner, it is easy to visualize and compare the relative importance of inputs to the final results of the model.

First, we examined correlation coefficients of stochastic variables with our primary metric of interest, NPV. In most cases, the actual stochastic variable itself was included in sensitivity analyses. However, in some cases, the RiskMakeInput function of @Risk was utilized to combine stochastic variables into a single input within sensitivity analyses. In this model, the RiskMakeInput function was used to summarize average simulated commodity prices across the ten-year time horizon to simplify interpretation 


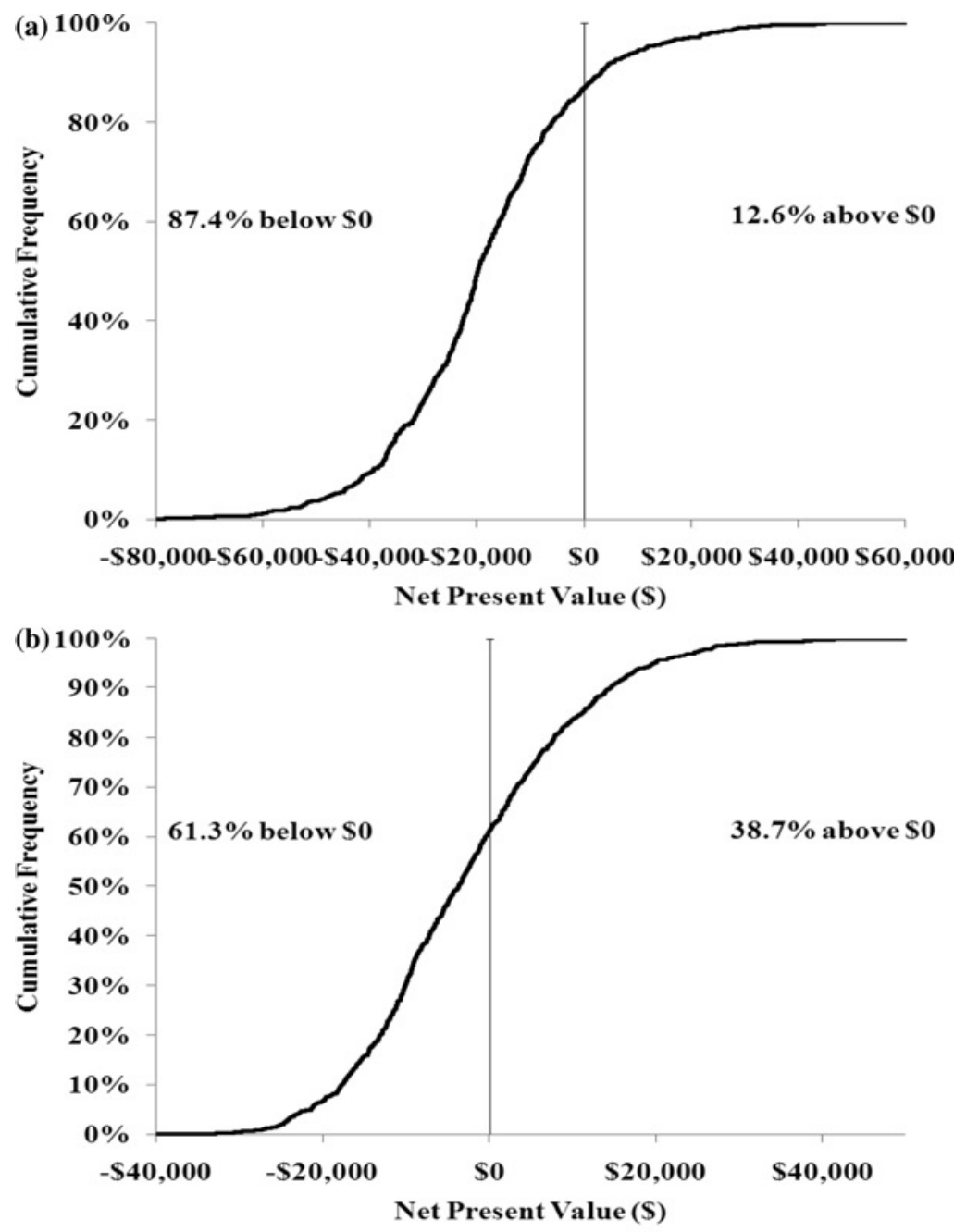

Notes: (a) All respondents and (b) selected respondents; selected respondents $(n=5)$ indicated a lower percentage of cows with BCS $\leq 3.25$ after technology adoption

\section{Dairy cattle body condition scoring system}

\section{1}

Figure 2.

CDF of NPV for simulations

of results. For example, the milk price in any one year would not likely impact the results of the final analysis; however, it is more plausible that an average of the simulated milk prices for the ten-year investment period could affect the NPV. Tornado diagrams for stochastic inputs for ALLSIM and LOWSIM using Spearman rank correlations are presented in Figure 4.

In both simulations, the stochastic variable that had the strongest relationship with NPV was the variable cost increase. Not surprisingly, as the variable costs per cow increased the NPV decreased in both simulations. Thus, the value of an automated BCS system was highly dependent on the costs incurred to utilize the information provided 


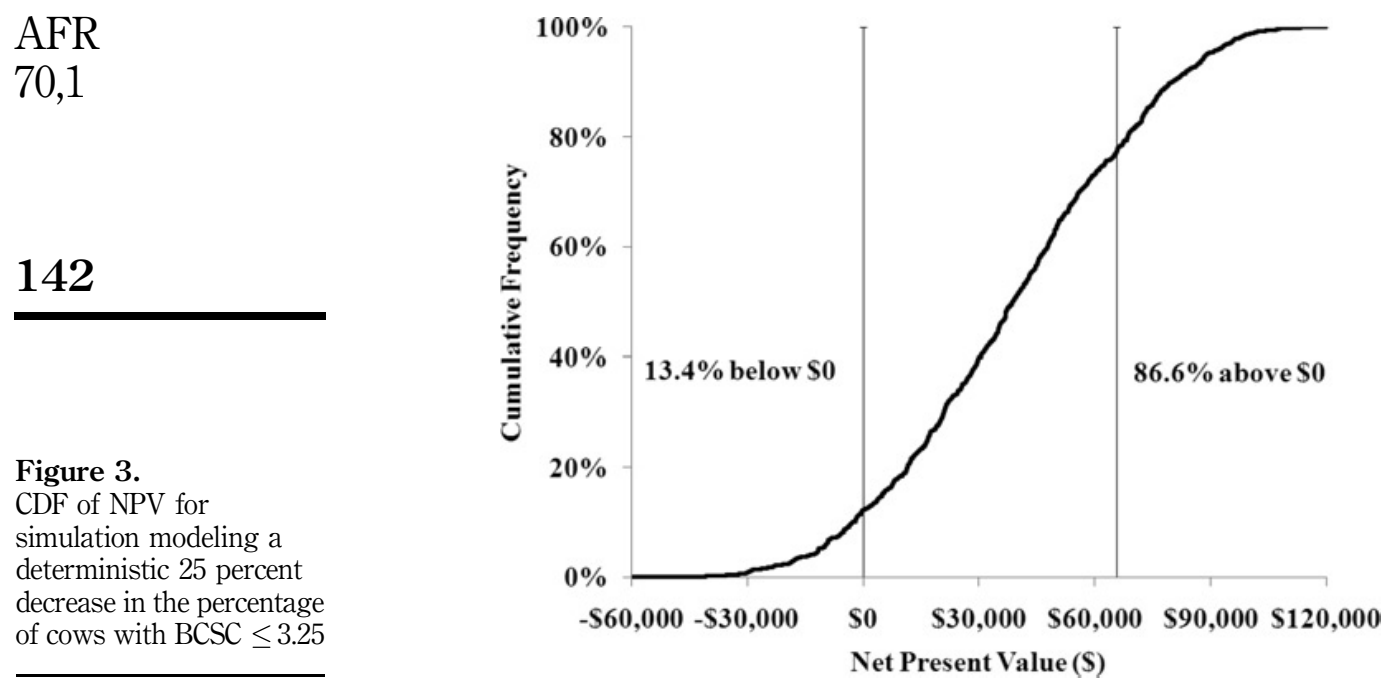

by the system to alter nutritional management for improved BCS profiles. In both ALLSIM and LOWSIM the next most important stochastic variables were those for the odds ratios for disease occurrence of varying BCS levels. The rank and direction of correlation varied considerably between the two simulations. For example, the Spearman rank correlation coefficient for the odds ratio for BCSC of 3.50-3.75 was -0.06 for ALLSIM indicating as the odds of ketosis for cows in this BCS range increased as the NPV decreased. Rank correlation coefficient for the odds ratio for BCSC of 3.50-3.75 was 0.05 for LOWSIM indicating as the odds of ketosis for cows in this BCS range increased the NPV also increased. This difference occurred because in the LOWSIM increasing the odds ratio for this category increased the advantages of the predicted reduction in BCSC, whereas in ALLSIM the increasing odds ratio exacerbated the negative effects of having more cows within the BCSC 3.50-3.75 range. The other stochastic variables that impacted NPV were those associated with uncertainty as to the actual cost of each case of disease from veterinary costs, labor, changes in DO, discarded milk, and unrealized milk production. Interestingly, none of the stochastic prices impacted the NPV. In an investment analysis over ten years, low prices in some years were balanced out by high prices in other years. If the investment analysis were performed over a shorter time frame, prices would be more likely to influence NPV.

Although they were not presented in the tornado diagram because their influence was accounted for in subsequent calculations, the effect of three other stochastic variables was examined: the cumulative percentage of cows with $\mathrm{BCSC} \leq 3.25$ and the odds ratios for conception at first service for cows with BCSFS $\leq 2.50$ and $\geq 3.50$. In both simulations, the NPV increased as the change in percentage of cows with $\mathrm{BCSC} \leq 3.25$ increased. This relationship was strong for both simulations but considerably higher for ALLSIM where more variation in BCSBEF and BCSAFT was modeled. Essentially, this indicates that the farms that would benefit the most from investing in an automated BCS system are those that have more cows calving with $\mathrm{BCS} \geq 3.50$ who successfully incorporate the BCS provided by the system to reduce the percentage of cows calving in excess condition. Increasing odds ratios for 
(a)

Variable Cost Increase Ketosis OR 4.00 to 4.25

Ketosis OR $\leq \mathbf{2 . 7 5}$

Ketosis OR 3.50 to 3.75

Metritis Veterinary Costs

Milk Fever Labor

Milk Fever OR $\geq 3.50$

Metritis Discard Milk

Ketosis OR $\geq 4.50$

Milk Fever Veterinary Costs

Metritis Labor Costs

Ketosis Labor Costs

Ketosis Days Open

Ketosis Veterinary Costs

Milk Fever OR 3.25
Milk Fever OR 2.75

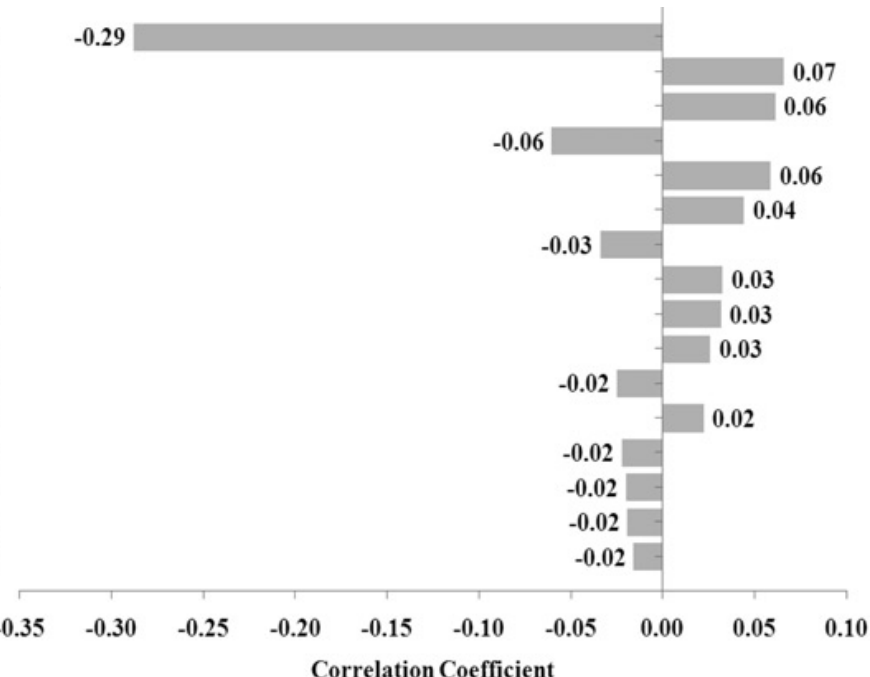

Correlation Coefficient (b) Variable Cost Increase Milk Fever $\mathrm{OR} \leq \mathbf{2 . 5 0}$

Ketosis OR $\leq \mathbf{2 . 7 5}$

Ketosis OR 3.50 to 3.75

Milk Fever OR $\geq 3.50$

Ketosis OR $\geq 4.50$

Metritis Days Open

Ketosis Days Open

Unrealized Milk Ketosis

Ketosis Veterinary Costs

Milk Fever Veterinary Costs

Milk Fever OR 2.75

Ketosis OR 4.00 to 4.25

Metritis Labor Costs

Milk Fever Labor

Milk Fever OR 3.25

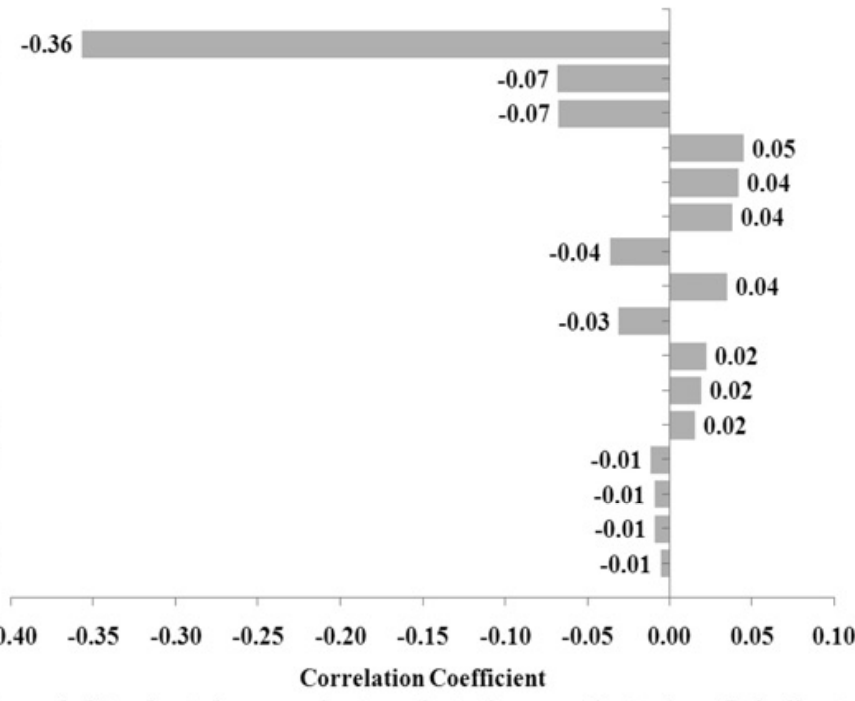

Notes: (a) All respondents and (b) selected respondents; selected respondents $(n=5)$ indicated a lower percentage of cows with BCS $\leq 3.25$ after technology adoption.; OR with BCS are stochastic odds ratios for cows within a BCS range, DO, labor, and veterinary costs are stochastic variables for disease costs.

conception for both BCSFS $\leq 2.50$ and $\geq 3.50$ were associated with decreased NPV for both ALLSIM and LOWSIM. This relationship indicates that when the effect of BCSFS on conception at first service was minimal, the NPV decreased because the advantages of changing BCS for reproductive performance were negligible. In LOWSIM, this relationship was particularly $(r=-0.68)$ strong for the odds ratio for $\mathrm{BCS} \geq 3.50$. Because these experts placed a premium on reducing the BCSC, the negative effects of poorer conception rates in overconditioned cows were increased considerably.

\section{Dairy cattle body condition scoring system}

Figure 4.

Tornado diagrams for stochastic factors with Spearman correlation coefficients impacting NPV for simulations 


\section{AFR 70,1}

In a regression tornado diagram, @ Risk runs a multiple regression analysis for each iteration with the output of interest as the dependent variable and the simulated values of each stochastic variable as independent variables. The resulting graphs depict beta coefficients, which demonstrate the amount of change in the dependent variable when the independent variable increases by one $\mathrm{SD}$ when all other variables are held constant. Again, the variables with the most influence are on the top of the graph progressing toward the variables with the least influence (Winston, 2001). In Figure 5, regression tornado diagrams are presented for the impact of the variable cost increase and odds ratios for ketosis and milk fever occurrence of varying BCS ranges on NPV. For ALLSIM, increasing variable costs by one SD decreased the NPV by $\$ 4,373.52$ and increasing the odds ratio for ketosis for cows with BCS 2.75 increased the NPV by $\$ 1,004.43$. For LOWSIM, increasing variable costs, the odds ratio for milk fever for cows with BCS of 2.50, and the odds ratio for ketosis for cows with BCS of 2.75, decreased the NPV by $\$ 4,614.17, \$ 1,031.16$, and $\$ 972.86$, respectively. Conversely, increasing the odds ratio for ketosis for cows with BCS of 3.50-3.75 and the odds ratio for ketosis for cows with BCS of 4.50 increased the NPV by $\$ 1,147.10$ and $\$ 703.19$, respectively.

Finally, the results of any simulation model are highly dependent on the assumptions within the model. A one-way sensitivity analysis tornado diagram compares multiple variables on the same graph. Essentially, each input is varied (one at a time) between feasible high and low values and the model is evaluated for the output at those levels holding all other inputs at their default levels. On the tornado diagram, for each input, the lower value is plotted at the left end of the bar and the higher value at the right end of the bar (Clemen, 1996). Simulations were run for high and low feasible values for five key inputs that may affect NPV using the predicted BCSBEF and BCSAFT from all survey respondents. As was previously mentioned, on average, investing in an automated system will result in a negative NPV because, using model assumptions, the general increase in BCS would result in an increase in disease incidence. Typically, in a tornado diagram, the mean NPV is plotted as in Figure 6(a). To illustrate sensitivity when the model predicts a decrease in BCS, we have also provided a tornado diagram for the NPV's at the 95th percentile for each of these five inputs (Figure 6(b)).

The first thing to keep in mind when looking at the mean NPV diagram (Figure 6a) is that all of the ranges predict a negative NPV, so for an individual farmer, the decision would be to not invest in the system regardless of any of these inputs. The most interesting result here was that herd size was the most sensitive variable but in the opposite direction one might expect as the NPV was higher (less negative) for the smaller herd than the larger herd. Generally, increasing herd size would improve the feasibility of investment in technology because of economies of scale. However, in this case, the average NPV for the larger herd was lower because of increased disease costs predicted in many iterations of the simulation resulting from higher herd BCS. The tornado diagram for the 95th percentile provides much more useful information (Figure 6(b)). Again, the most sensitive variable was herd size; however, this time the relationship was as expected. The NPV was higher for the larger herd because the investment costs and benefits were spread among more cows. The next most important variable was the BMPAF. Again, this result was not surprising and reiterates that one of the most important determinants of project success was what the producer actually does to manage the information provided by the technology. There are many nutritional, health, reproductive, and environmental decisions made by the dairy 
(a)

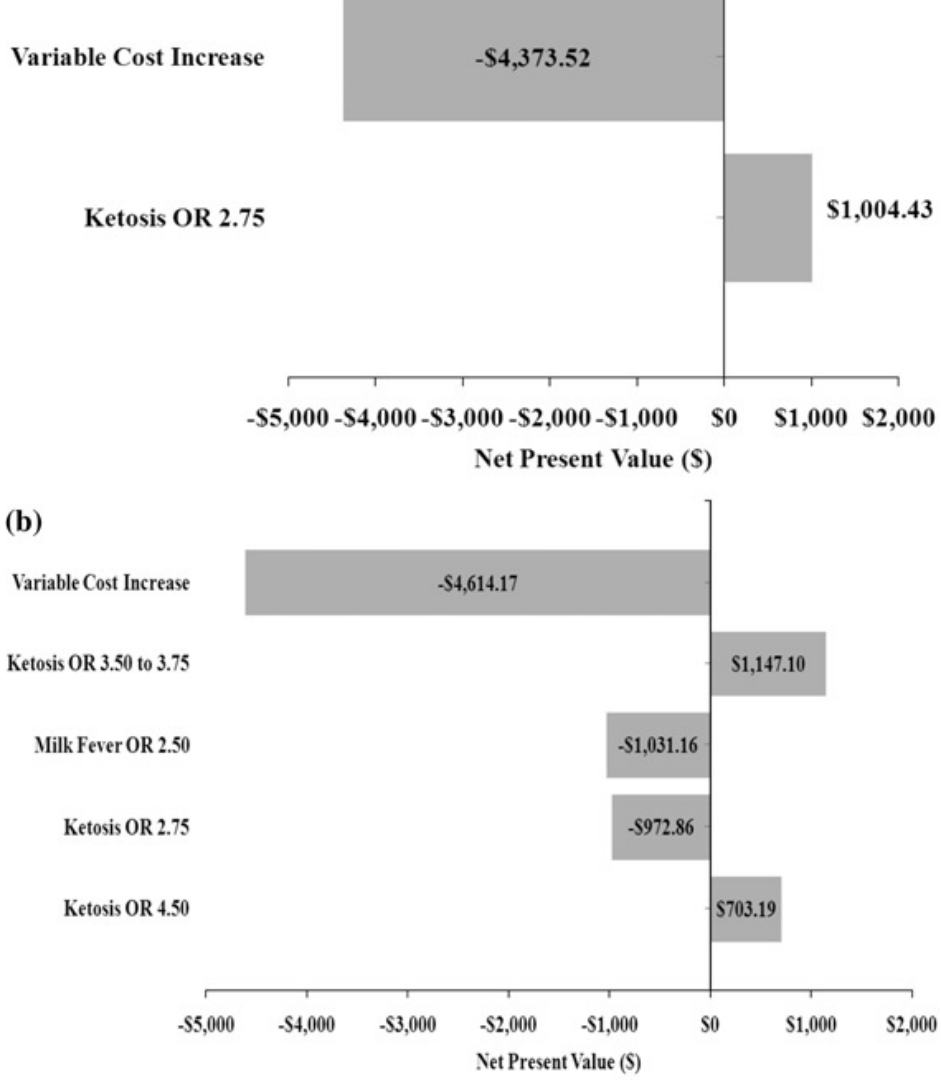

Notes: (a) all respondents and (b) selected respondents; selected respondents $(n=5)$ indicated a lower percentage of cows with BCS $\leq 3.25$ after technology; adoption.OR with BCS are stochastic odds ratios for cows within a BCS range. (b)

\section{Ketosis OR 3.50 to 3.75 \\ Iilk Fever OR 2.50}

Ketosis OR 2.75

\section{.50}

\section{Dairy cattle body condition scoring system}


AFR

70,1

146 (a)

Number of cows $\quad 5,000$

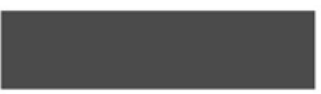

50

Purchase price

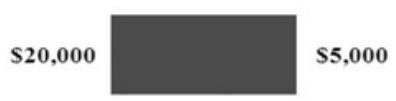

BMPAF

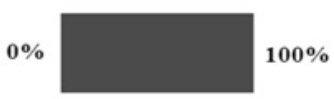

RHA milk production

$4,223 \mathrm{~kg}$

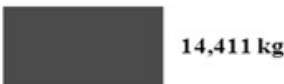

Ketosis incidence

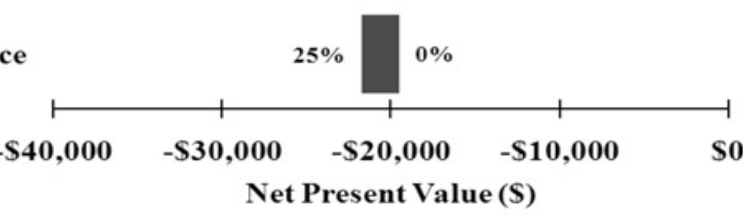

(b)

Number of cows

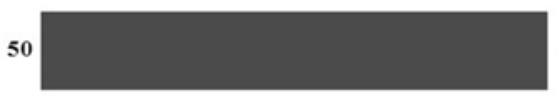

5,000

BMPAF

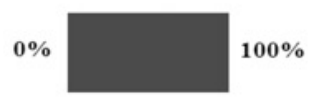

RHA milk production

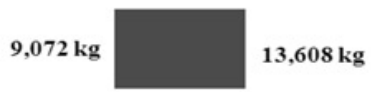

Purchase price

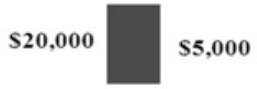

Figure 6.

Tornado diagrams for deterministic factors affecting the mean (a) and 95th percentile of NPV for simulations using the estimates of all survey respondents

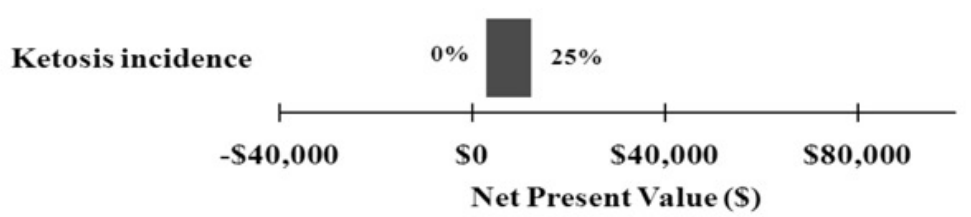

Notes: BMPAF is the Best Management Practice Adherence Factor, RHA milk production is rolling herd average milk production in $\mathrm{kg}$.

increased with an increased base incidence of ketosis because the effects of BCS on ketosis would be exaggerated.

Limitations and further work

Prior to this modeling exercise, given the losses from diseases generally attributed to BCS outside of optimal ranges, we expected that adoption of this technology would have proven beneficial in most scenarios. However, as previously mentioned, the disconnect between the expert opinion assessments and the effects of BCS on disease and conception rates obtained from the literature had a major effect on these results. Further, in an effort to minimize the chances of overestimating the value of the 
technology, the estimates we used were generally conservative. In addition to the effects of reducing disease incidence and conception rates at first service, improved management of BCS would also likely reduce the impact of disease that does occur and influence conception rates at subsequent services. Given the current state of knowledge, these estimates would be nearly impossible to calculate. Moreover, though literature estimates are highly variable (hence our decision not to include them in this model) detecting changes in BCS would likely impact other diseases (e.g. retained placenta, lameness) either directly or indirectly. The benefits of automated BCS for animal well-being and genetics would be even more difficult to quantify. On the other hand, it would be unrealistic to think that the technology would be beneficial to all dairy producers in all situations. If a dairy is already doing a good job of managing $\mathrm{BCS}$, there would be few benefits of investing in this technology and this is reflected in the LOWSIM results. Conversely, as Figure 3 demonstrates, a dairy with room for improvement would benefit from investment in almost all situations.

Dairy producers and consultants are accustomed to seeing results from deterministic economic analyses with only two possible outcomes. Examining decisions with a stochastic simulation model accounts for more of the risk and uncertainty characteristic of the dairy system. Given this risk and uncertainty, a stochastic investment analysis will represent that there is uncertainty in the profitability of some projects. Ultimately, the dairy manager's level of risk aversion will determine whether or not he or she invests in a technology using the results from this type of analysis.

\section{Conclusions}

The profitability of investment in an automated BCS system was highly dependent on the current BCS distribution of the herd, the magnitude of negative impacts of low or high BCS, and the ability of management to make changes necessary to achieve optimal BCS. Certainly, some herds would benefit from investment in this technology. As the technology matures, additional knowledge with regard to the specific benefits from frequent BCS will be gained which could improve estimates in the investment decision model and tighten correlations of BCS with health incidence collected serially. This investment decision can be analyzed using herd-specific values with this model.

\section{References}

Banos, G., Coffey, M.P., Wall, E. and Brotherstone, S. (2006), "Genetic relationship between firstlactation body energy and later-life udder health in dairy cattle", Journal of Dairy Science, Vol. 89, pp. 2222-32.

Bewley, J.M., Boehlje, M.D., Gray, A.W., Hogeveen, H., Kenyon, S.J., Eicher, S.D. and Schutz, M.M. (2010), "Stochastic simulation using @ Risk for dairy business investment decisions", Agricultural Finance Review, Vol. 70 No. 1, pp. 97-125.

Bewley, J.M., Peacock, A.M., Lewis, O., Boyce, R.E., Roberts, D.J., Coffey, M.P., Kenyon, S.J. and Schutz, M.M. (2008), "Potential for estimation of body condition scores in dairy cattle using digital images", Journal of Dairy Science, Vol. 91, pp. 3439-53.

Boehlje, M. and Ehmke, C. (2005), Capital Investment Analysis and Project Assessment, Purdue Extension Agricultural Innovation and Commercialization Center, West Lafayette, IN.

Braun, R.K., Donovan, G.A., Tran, T.Q., Mohammed, H.O. and Webb, D.W. (1987), "Importance of body condition scoring in dairy cattle", The Bovine Proceedings, Vol. 19, pp. 122-6.

Broster, W.H. and Broster, V.J. (1998), "Body score of dairy cows", Journal of Dairy Research, Vol. 65, pp. 155-73.

\section{Dairy cattle body condition scoring system}


AFR 70,1

Busato, A., Faissler, D., Kupfer, U. and Blum, J.W. (2002), "Body condition scores in dairy cows: associations with metabolic and endocrine changes in healthy dairy cows", Journal of Veterinary Medicine Series A, Vol. 49, pp. 455-60.

Chagas, L.M., Bass, J.J., Blache, D., Burke, C.R., Kay, J.K., Lindsay, D.R., Lucy, M.C., Martin, G.B., Meier, S., Rhodes, F.M., Roche, J.R., Thatcher, W.W. and Webb, R. (2007), "Invited review: new perspectives on the roles of nutrition and metabolic priorities in the subfertility of high-producing dairy cows", Journal of Dairy Science, Vol. 90, pp. 4022-32.

Clemen, R.T. (1996), Making Hard Decisions: An Introduction to Decision Analysis, Duxbury Press, Belmont, CA.

Coffey, M.P. (2003), "A phenotypic and genetic analysis of energy balance in dairy cows", $\mathrm{PhD}$ dissertation, University of Edinburgh, Edinburgh.

Coffey, M.P., McFarlane, N. and Mottram, T. (2003a), "The feasibility of automatic condition scoring", Holstein Journal, Vol. 66, April, pp. 82-3.

Coffey, M.P., Simm, G., Hill, W.G. and Brotherstone, S. (2003b), "Genetic evaluations of dairy bulls for daughter energy balance profiles using linear type scores and body condition score analyzed using random regression", Journal of Dairy Science, Vol. 86, pp. 2205-12.

Coffey, M.P., Simm, G., Oldham, J.D., Hill, W.G. and Brotherstone, S. (2004), "Genotype and diet effects on energy balance in the first three lactations of dairy cows", Journal of Dairy Science, Vol. 87, pp. 4318-26.

Contreras, L.L., Ryan, C.M. and Overton, T.R. (2004), "Effects of dry cow grouping strategy and prepartum body condition score on performance and health of transition dairy cows", Journal of Dairy Science, Vol. 87, pp. 517-23.

Delorenzo, M.A. and Thomas, C.V. (1996), "Dairy records and models for economic and financial planning", Journal of Dairy Science, Vol. 79, pp. 337-45.

Emmans, G.G. (1994), "Effective energy: a concept of energy utilization applied across species", British Journal of Nutrition, Vol. 71, pp. 801-21.

FAPRI (2007), "FAPRI (Food and Agricultural Policy Research Institute) 2007 US and World Agricultural Outlook", in Missouri-Columbia, I.S.U.a.U.o. (Eds), Ames, IA, available at: www.fapri.iastate.edu/outlook/2007/text/OutlookPub2007.pdf

Ferguson, J.D. (2001), "Nutrition and reproduction in dairy herds", Proceedings of the 2001 Intermountain Nutrition Conference, Salt Lake City, UT, Utah State Univ., Logan, pp. 65-82.

Ferguson, J.D. (2002), "Body condition scoring”, Proceedings of the Mid-South Ruminant Nutrition Conference, Arlington, TX, pp. 56-63.

Ferguson, J.O., Galligan, D.T. and Thomsen, N. (1994), "Principal descriptors of body condition score in Holstein cows", Journal of Dairy Science, Vol. 77, pp. 2695-703.

Friggens, N.C., Ingvartsen, K.L. and Emmans, G.C. (2004), "Prediction of body lipid change in pregnancy and lactation”, Journal of Dairy Science, Vol. 87, pp. 988-1000.

Garnsworthy, P.C. (2007), "Body condition score in dairy cows: targets for production and fertility", in Garnsworthy, P.C. and Wiseman, J. (Eds), Recent Advances in Animal Nutrition 2006, University of Nottingham Press, Nottingham, pp. 61-86.

Gillund, P., Reksen, O., Grohn, Y.T. and Karlberg, K. (2001), "Body condition related to ketosis and reproductive performance in Norwegian dairy cows", Journal of Dairy Science, Vol. 84, pp. 1390-6.

Hady, P.J., Domecq, J.J. and Kaneene, J.B. (1994), "Frequency and precision of body condition scoring in dairy cattle", Journal of Dairy Science, Vol. 77, pp. 1543-7.

Heuer, C., Schukken, Y.H. and Dobbelaar, P. (1999), "Postpartum body condition score and results from the first test day milk as predictors of disease, fertility, yield, and culling in commercial dairy herds", Journal of Dairy Science, Vol. 82, pp. 295-304. 
Jones, H.E., White, I.M.S. and Brotherstone, S. (1999), "Genetic evaluation of Holstein Friesian sires for daughter condition-score changes using a random regression model”, Animal Science, Vol. 68, pp. 467-75.

Kristensen, E., Dueholm, L., Vink, D., Andersen, J.E., Jakobsen, E.B., Illum-Nielsen, S., Petersen, F.A. and Enevoldsen, C. (2006), "Within- and across-person uniformity of body condition scoring in Danish Holstein cattle”, Journal of Dairy Science, Vol. 89, pp. 3721-8.

Leroy, T., Aerts, J.M., Eeman, J., Maltz, E., Stojanovski, G. and Berckmans, D. (2005), "Automatic determination of body condition score of cows based on 2D images", in Cox, S. (Ed.), Precision Livestock Farming, Wageningen Academy Publishers, Wageningen, pp. 251-5.

Loeffler, S.H., de Vries, M.J., Schukken, Y.H., de Zeeuw, A.C., Dijkhuizen, A.A., de Graaf, F.M. and Brand, A. (1999), "Use of AI technician scores for body condition, uterine tone and uterine discharge in a model with disease and milk production parameters to predict pregnancy risk at first AI in Holstein dairy cows", Theriogenology, Vol. 51, pp. 1267-84.

NRC (2001), Nutrient Requirements of Dairy Cattle, 7th rev. ed., National Academy Press, Washington, DC.

Perkins, B.L., Smith, R.D. and Sniffen, C.J. (1985), "Troubleshooting your herd with the body condition scoring system", Cornell Cooperative Extension Dairy Management Fact Sheet, Vol. 151.

Pompe, J.C.A.M., de Graaf, V.J., Semplonius, R. and Meuleman, J. (2005), "Automatic body condition scoring of dairy cows: extracting contour lines", Book of Abstracts 5 ECPA$2 E C P L F$, JTI-/Swedish Institute of Agricultural and Environmental Engineering, Uppsala, pp. 243-5.

Roche, J.R. and Berry, D.P. (2006), "Periparturient climatic, animal, and management factors influencing the incidence of milk fever in grazing systems", Journal of Dairy Science, Vol. 89, pp. 2775-83.

Schwager-Suter, R. (1999), "Efficiency of dairy cows differing in body size when feed quality is varied", Swiss Federal Institute of Technology, Zurich.

Skidmore, A.L. (1990), "Development of a simulation model to evaluate effectiveness of dairy herd management", Cornell University, Ithaca, NY, p. 236.

Spain, J. (1996), "Optimal body condition score at calving for production and health", Western Canadian Dairy Seminar, pp. 11-20.

Streeter, D.H. and Hornbaker, R.H. (1993), "Value of information systems: alternative viewpoints and illustrations", in Farm Level Information Systems, Wageningen Academy Publishers, Wageningen, pp. 283-93.

Upham, G. (1990), "Use of body condition scores in grouping lactating cows", Compendium on Continuing Education for the Practicing Veterinarian, Vol. 12, pp. 581-9.

van Asseldonk, M.A.P.M. (1999), "Economic evaluation of information technology applications on dairy farms", PhD dissertation, Wageningen University, p. 123.

van Asseldonk, M.A.P.M., Jalvingh, A.W., Huirne, R.B.M. and Dijkhuizen, A.A. (1999), "Potential economic benefits from changes in management via information technology applications on Dutch dairy farms: a simulation study", Livestock Production Science, Vol. 60, pp. 33-44.

Vose, D. (2000), Risk Analysis. A Quantitative Guide, John Wiley and Sons, New York, NY.

Wall, E., Coffey, M.P. and Amer, P.R. (2008), "A theoretical framework for deriving direct economic values for body tissue mobilization traits in dairy cattle”, Journal of Dairy Science, Vol. 91, pp. 343-53.

Wall, E., Coffey, M.P. and Brotherstone, S. (2007), "The relationship between body energy traits and production and fitness traits in first-lactation dairy cows", Journal of Dairy Science, Vol. 90, pp. 1527-37.

\section{Dairy cattle body condition scoring system}


Waltner, S.S., McNamara, J.P. and Hillers, J.K. (1993), "Relationships of body condition score to production variables in high producing Holstein dairy cattle", Journal of Dairy Science, Vol. 76, pp. 3410-9.

Winston, W.L. (2001), Simulation Modeling Using @Risk: Updated for Version 4, Duxbury Press, Pacific Grove, CA.

\section{About the authors}

J.M. Bewley is affiliated with the Department of Animal Sciences, Purdue University, West Lafayette, Indiana, USA and Department of Animal and Food Sciences, University of Kentucky, Lexington, Kentucky, USA. J.M. Bewley is the corresponding author and can be contacted at: jbewley@uky.edu

M.D. Boehlje and A.W. Gray are affiliated with the Department of Agricultural Economics, Purdue University, West Lafayette, Indiana, USA.

H. Hogeveen is affiliated with the Faculty Veterinary Medicine, Utrecht University, Utrecht, The Netherlands.

S.J. Kenyon is affiliated with the Department of Veterinary Clinical Sciences, Purdue University, West Lafayette, Indiana, USA.

S.D. Eicher is affiliated with the Livestock Behavior Research Unit, Agricultural Research Service, USDA, West Lafayette, Indiana, USA.

M.M. Schutz is affiliated with the Department of Animal Sciences, Purdue University, West Lafayette, Indiana, USA.

To purchase reprints of this article please e-mail: reprints@emeraldinsight.com Or visit our web site for further details: www.emeraldinsight.com/reprints 